Supporting Information

\title{
Melatonin- and Ferulic Acid-Based HDAC6 Selective Inhibitors Exhibit Pronounced Immunomodulatory Effects in Vitro and Neuroprotective Effects in a Pharmacological Alzheimer's Disease Mouse Model
}

Feng $\mathrm{He}^{\dagger}$, C. James Chou ${ }^{\ddagger}$, Matthias Scheiner ${ }^{\dagger}$, Eleonora Poeta ${ }^{\S}$, Natalia Yuan Chen ${ }^{\dagger}$, Sandra Gunesch ${ }^{\dagger}$, Matthias Hoffmann ${ }^{\dagger}$, Christoph Sotriffer ${ }^{\dagger}$, Barbara Monti ${ }^{\S}$, Tangui

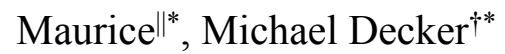

${ }^{\dagger}$ Pharmaceutical and Medicinal Chemistry, Institute of Pharmacy and Food Chemistry, Julius Maximilian University of Würzburg, Am Hubland, 97074 Würzburg, Germany

tDepartment of Drug Discovery and Biomedical Sciences, South Carolina College of Pharmacy, Medical University of South Carolina, Charleston, South Carolina 29425, United States

$\S$ Department of Pharmacy and Biotechnologies, University of Bologna, Via Selmi 3, 40126, Bologna, Italy

"MMDN, Univ. Montpellier, EPHE, INSERM, Montpellier, France 


\section{Content}

$\begin{array}{ll}\text { HPLC-Chromatograms of target compounds } & \text { S3 }\end{array}$

$\begin{array}{ll}\text { Metal chelation } & \text { S10 }\end{array}$

$\begin{array}{ll}\text { Neuroprotection regarding oxytosis and ATP depletion } & \text { S11 }\end{array}$

$\begin{array}{ll}\text { Weight of animals during in vivo studies } & \text { S12 }\end{array}$

$\begin{array}{ll}\text { Computational docking } & \text { S13 }\end{array}$ 


\section{HPLC CHROMATOGRAMS OF TARGET COMPOUNDS}

Measurements for verification and purity of the compounds were performed by LC/MS (from Shimadzu), comprising a DGU-20A3R controller, pump LC-20AB, degasser DGU-20A, and SPD20A UV/Vis detector. ESI ionization was accomplished by an LCMS-2020 single quadrupol mass spectrometer. As a stationary phase, for analytical purpose, a Synergi $4 \mathrm{U}$ fusion-RP $80 \AA$ (150 × $4.6 \mathrm{~mm})$ column and for preparative purpose, a Synergi $4 \mathrm{U}$ fusion-RP $80 \AA(250 \times 10.0 \mathrm{~mm})$ were used. As a mobile phase, a gradient of $\mathrm{MeOH} /$ water (both containing $0.1 \%$ formic acid) (phase 1/phase 2) was used. The compounds were dissolved in $\mathrm{MeOH}$ and filtered through syringe filters. Methods were performed with a flow rate of $1.0 \mathrm{~mL} / \mathrm{min}$.

Method A: $V(1) /(V(1)+V(2))=$ from 0 to $60 \%$ over 10 min, $V(1) /(V(1)+V(2))=60 \%$ for 5 $\min , \mathrm{V}(1) /(\mathrm{V}(1)+\mathrm{V}(2))=$ from 60 to $0 \%$ over $3 \mathrm{~min}$, used by compounds $\mathbf{3 a - 3 b}, \mathbf{5 a - 5 d}$ and $\mathbf{8 a - 8 c}$.

Method B: $\mathrm{V}(1) /(\mathrm{V}(1)+\mathrm{V}(2))=$ from 5 to $90 \%$ over $10 \mathrm{~min}, \mathrm{~V}(1) /(\mathrm{V}(1)+\mathrm{V}(2))=90 \%$ for 5 min, $\mathrm{V}(1) /(\mathrm{V}(1)+\mathrm{V}(2))=$ from 90 to $5 \%$ over 3 min, used by compound 10a-10c and 15a-15c.

\section{3a}

$\mathrm{mV}$

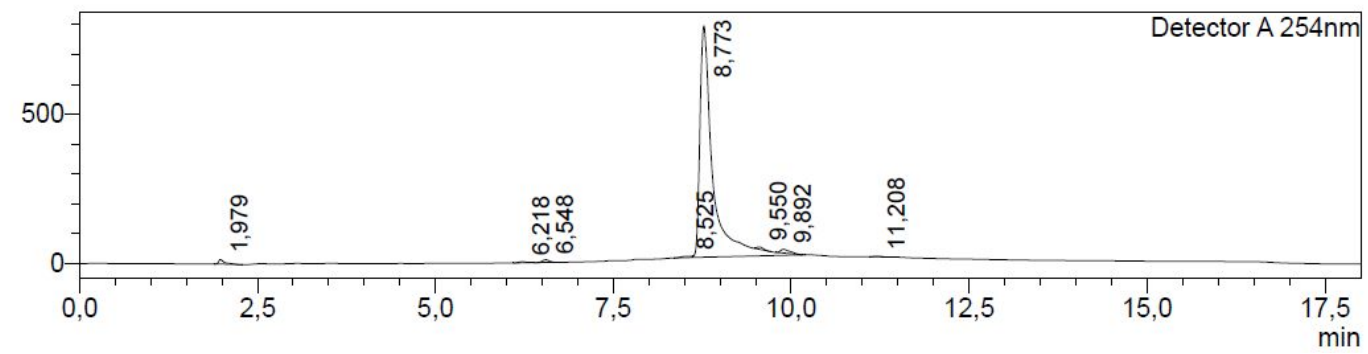

\begin{tabular}{|c|c|c|c|c|}
\hline Peak\# & Ret. Time & Area & Height & Area \% \\
\hline & 1.979 & 91134 & 14946 & 0.888 \\
\hline & 6.218 & 28119 & 3525 & 0.274 \\
\hline 3 & 6.548 & 61863 & 8950 & 0,603 \\
\hline 4 & 8,525 & 46530 & 4830 & 0.454 \\
\hline 5 & 8.773 & 9852949 & 773899 & 96.057 \\
\hline 6 & 9.550 & 44756 & 7343 & 0.436 \\
\hline 7 & 9.892 & 116358 & 12659 & 1.134 \\
\hline 8 & 11,208 & 15685 & 2438 & 0,153 \\
\hline Tota & & 10257395 & 828590 & 100.000 \\
\hline
\end{tabular}




\section{3b}

$\mathrm{mV}$

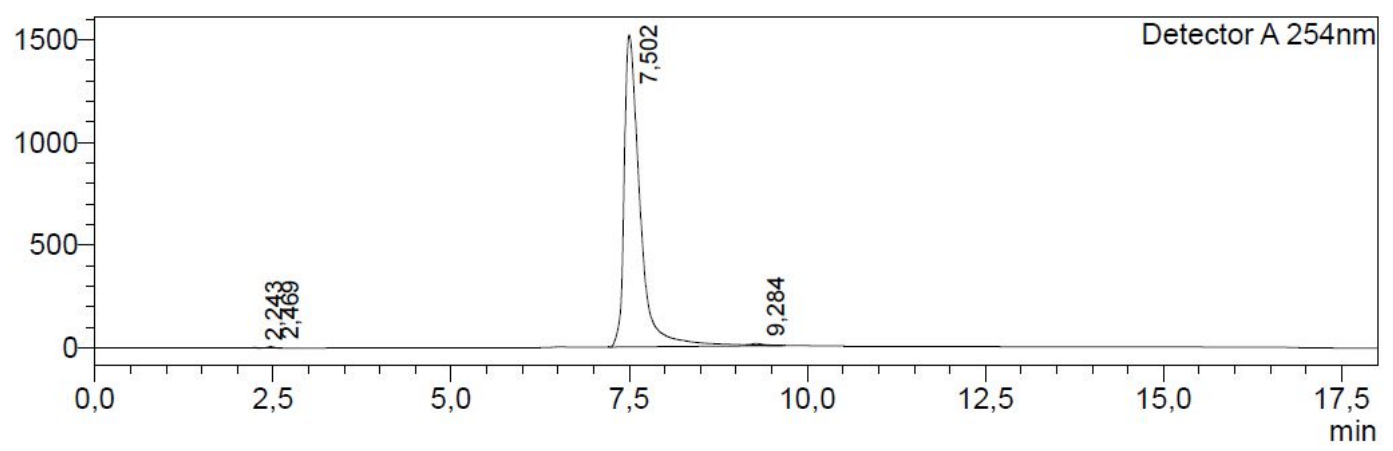

\begin{tabular}{|r|r|r|r|}
\hline Peak\# & Ret. Time & \multicolumn{1}{|c|}{ Area } & \multicolumn{1}{|c|}{ Area\% } \\
\hline 1 & 2,243 & 12994 & 0,055 \\
\hline 2 & 2,469 & 45937 & 0,194 \\
\hline 3 & 7,502 & 23532488 & 99,420 \\
\hline 4 & 9,284 & 78266 & 0,331 \\
\hline Total & & 23669684 & 100,000 \\
\hline
\end{tabular}

\section{$5 a$}

$\mathrm{mV}$

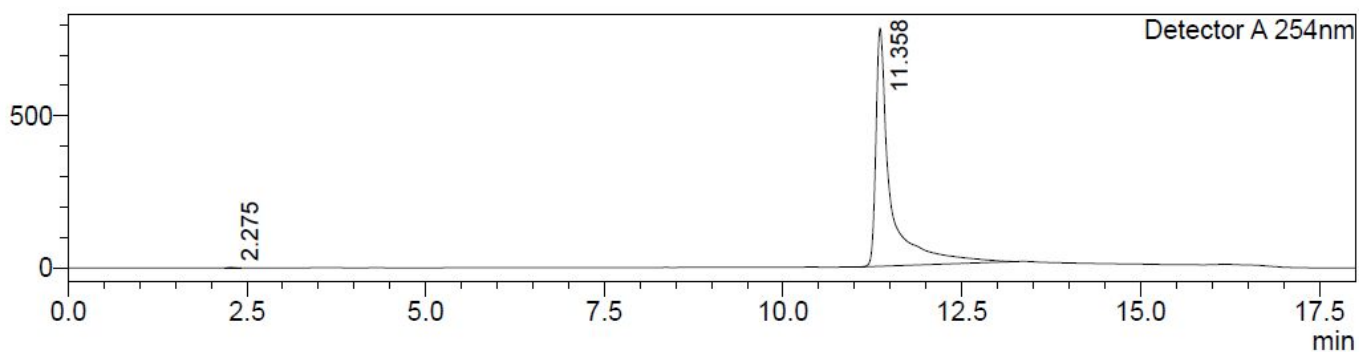

Peak Table

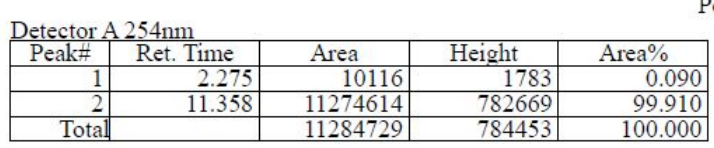

\section{$5 b$}

$\mathrm{mV}$

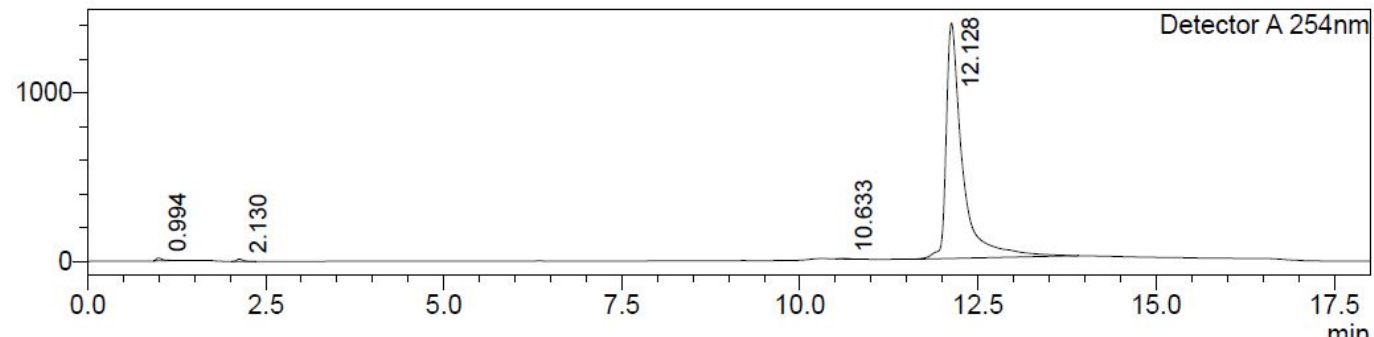

Peak Table

Detector A 254nm
\begin{tabular}{|r|r|r|r|r|}
\hline Peak\# & Ret. Time & Area & Height & Area $\%$ \\
\hline 1 & 0.994 & 97056 & 16898 & 0.429 \\
\hline 2 & 2.130 & 76672 & 13324 & 0.339 \\
\hline 3 & 10.633 & 28457 & 3515 & 0.126 \\
\hline 4 & 12.128 & 22415393 & 1395632 & 99.106 \\
\hline Total & & 22617578 & 1429369 & 100.000 \\
\hline
\end{tabular}


$5 c$

$\mathrm{mV}$

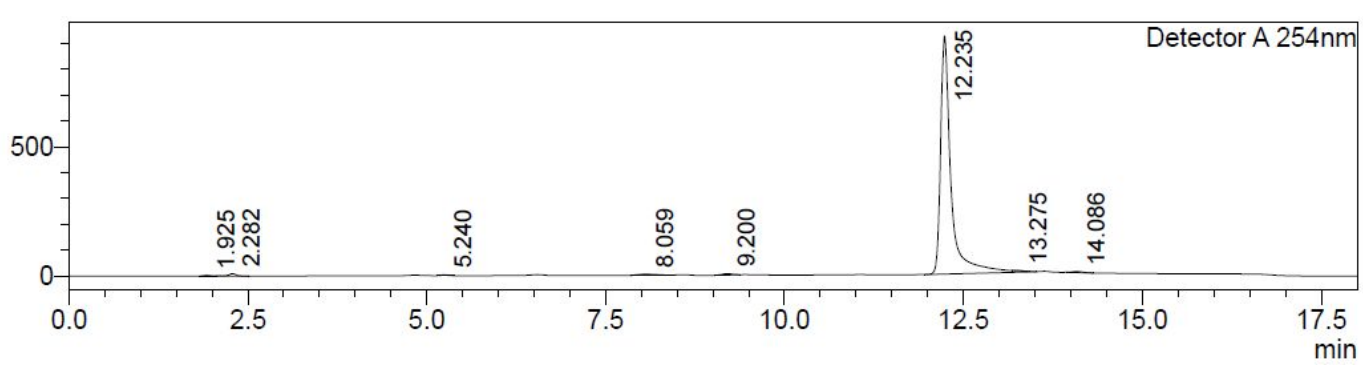

Peak Table

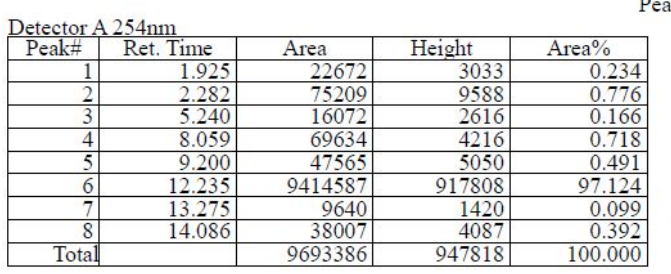

\section{5d}

$\mathrm{mV}$

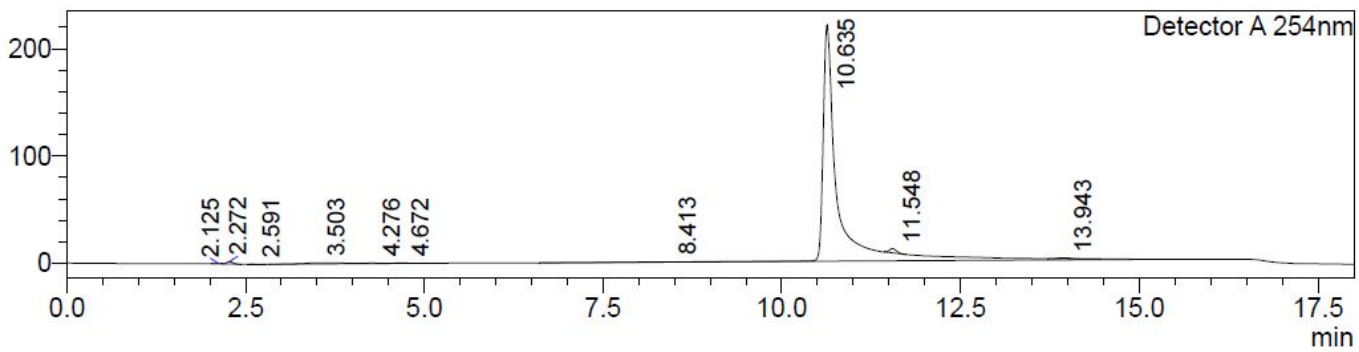

Peak Table

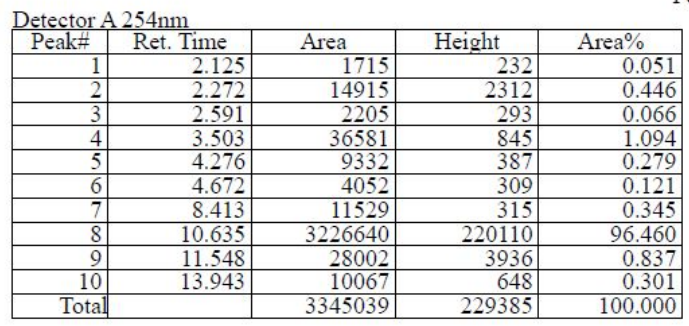




\section{$8 a$}

$\mathrm{mV}$

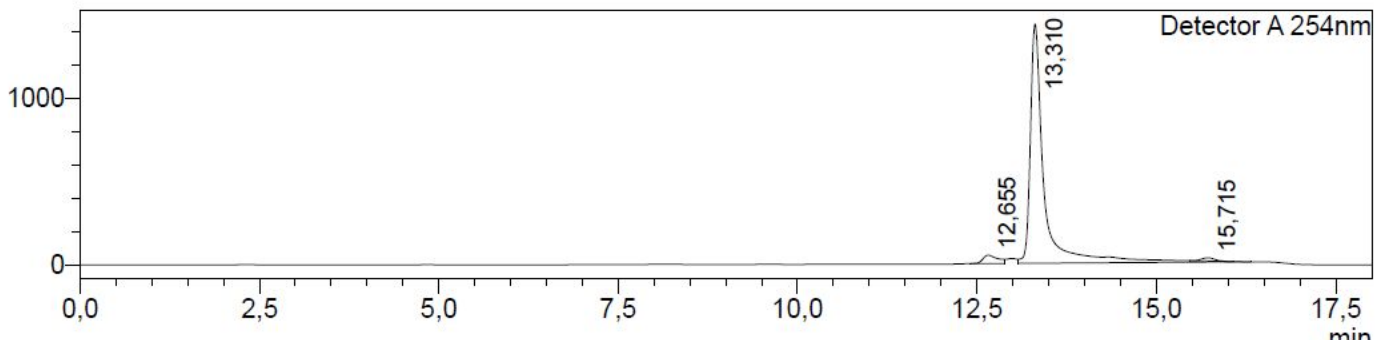

Peak Table

Detector A $254 \mathrm{~nm}$
\begin{tabular}{|r|r|r|r|r|}
\hline Peak\# & Ret. Time & \multicolumn{1}{|c|}{ Area } & Height & \multicolumn{1}{c|}{ Area $\%$} \\
\hline 1 & 12.655 & 726858 & 50478 & 3.570 \\
\hline 2 & 13.310 & 19383459 & 1431528 & 95.193 \\
\hline 3 & 15.715 & 251988 & 19495 & 1.238 \\
\hline Total & & 20362306 & 1501501 & 100.000 \\
\hline
\end{tabular}

\section{$8 b$}

$\mathrm{mV}$

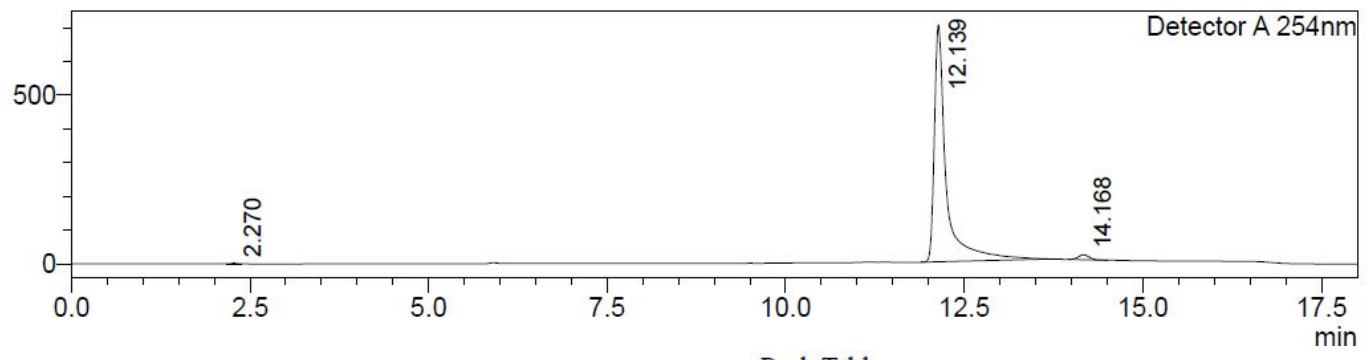

Peak Table

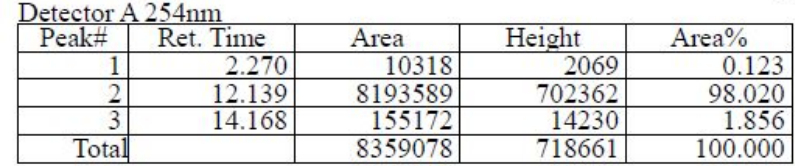

$8 c$

$\mathrm{mV}$

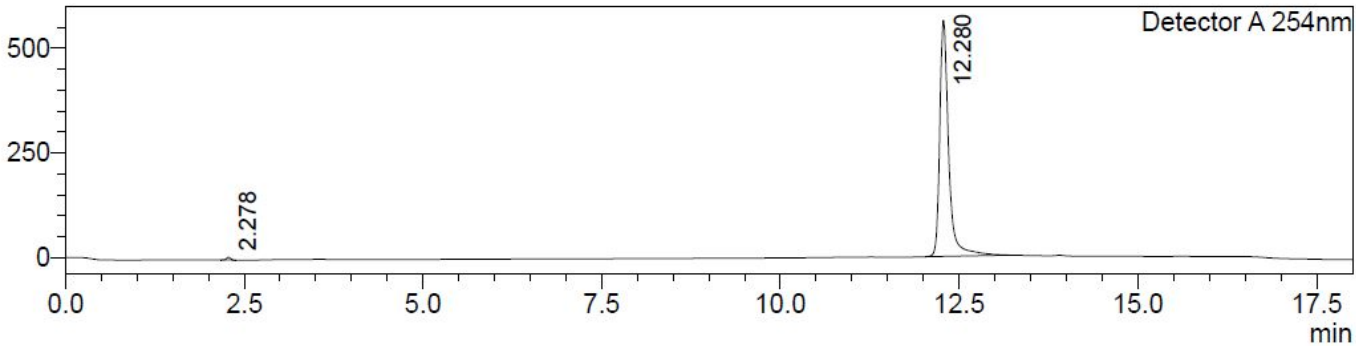

Peak Table

Detector A $254 \mathrm{~nm}$
\begin{tabular}{|r|r|r|r|r|}
\hline Peakk & Ret. Time & Area & Height & \multicolumn{1}{c|}{ Area $\%$} \\
\hline 1 & 2.278 & 26933 & 6711 & 0.544 \\
\hline 2 & 12.280 & 4924022 & 56738 & 99.456 \\
\hline Total & & 4950955 & 570450 & 100.000 \\
\hline
\end{tabular}




\section{$10 a$}

$\mathrm{mV}$

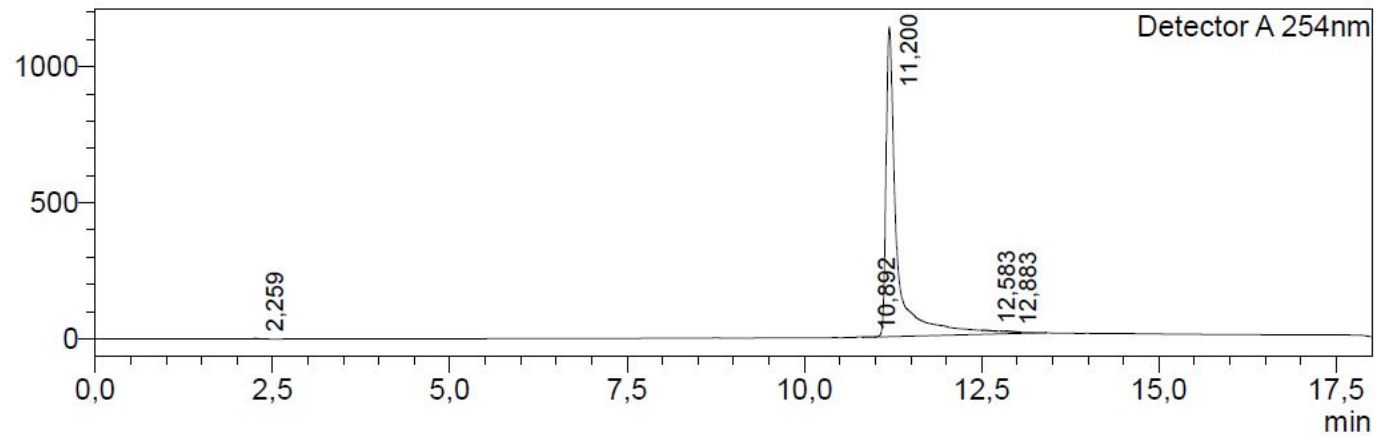

\begin{tabular}{|r|r|r|r|}
\hline Peak\# & Ret. Time & \multicolumn{1}{|c|}{ Area } & \multicolumn{1}{c|}{ Area $\%$} \\
\hline 1 & 2,259 & 7992 & 0,064 \\
\hline 2 & 10,892 & 3397 & 0,027 \\
\hline 3 & 11,200 & 12455737 & 99,770 \\
\hline 4 & 12,583 & 5127 & 0,041 \\
\hline 5 & 12,883 & 12159 & 0,097 \\
\hline Total & & 12484411 & 100,000 \\
\hline
\end{tabular}

\section{$10 b$}

$\mathrm{mV}$

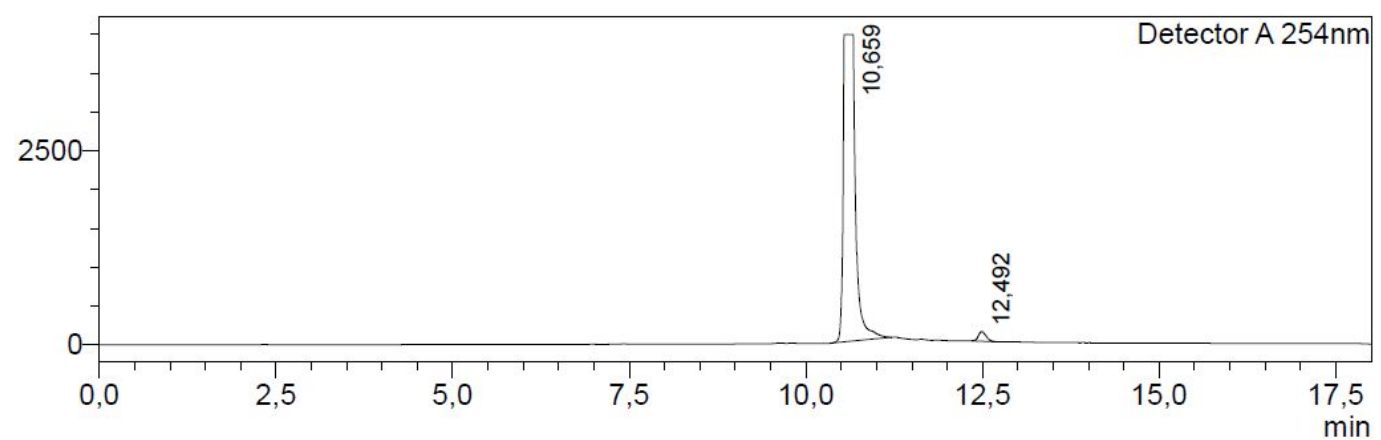

\begin{tabular}{|r|r|r|r|}
\hline \multicolumn{1}{|c|}{ Peak\# } & Ret. Time & \multicolumn{1}{c|}{ Area } & \multicolumn{1}{c|}{ Area\% } \\
\hline 1 & 10,659 & 47010198 & 98,056 \\
\hline 2 & 12,492 & 932079 & 1,944 \\
\hline Total & & 47942277 & 100,000 \\
\hline
\end{tabular}




\section{0c}

$\mathrm{mV}$

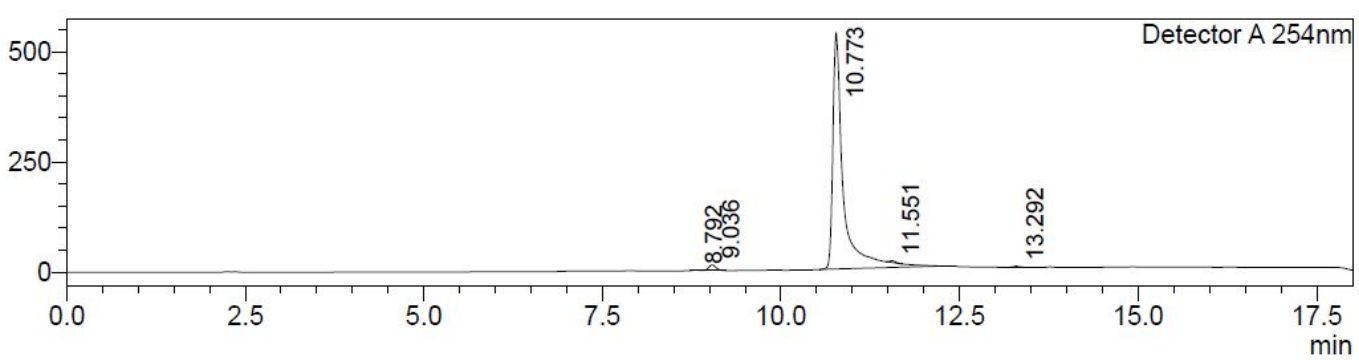

Peak Table

Detector A $254 \mathrm{~nm}$
\begin{tabular}{|r|r|r|r|r|}
\hline Peak\# & Ret. Time & \multicolumn{1}{|c|}{ Area } & Height & Area $\%$ \\
\hline 1 & 8.792 & 9253 & 1196 & 0.164 \\
\hline 2 & 9.036 & 91536 & 12838 & 1.620 \\
\hline 3 & 10.773 & 5514062 & 535257 & 97.611 \\
\hline 4 & 11.551 & 19917 & 3457 & 0.353 \\
\hline 5 & 13.292 & 14226 & 2283 & 0.252 \\
\hline Total & & 5648993 & 555031 & 100.000 \\
\hline
\end{tabular}

\section{$15 a$}

$\mathrm{mV}$

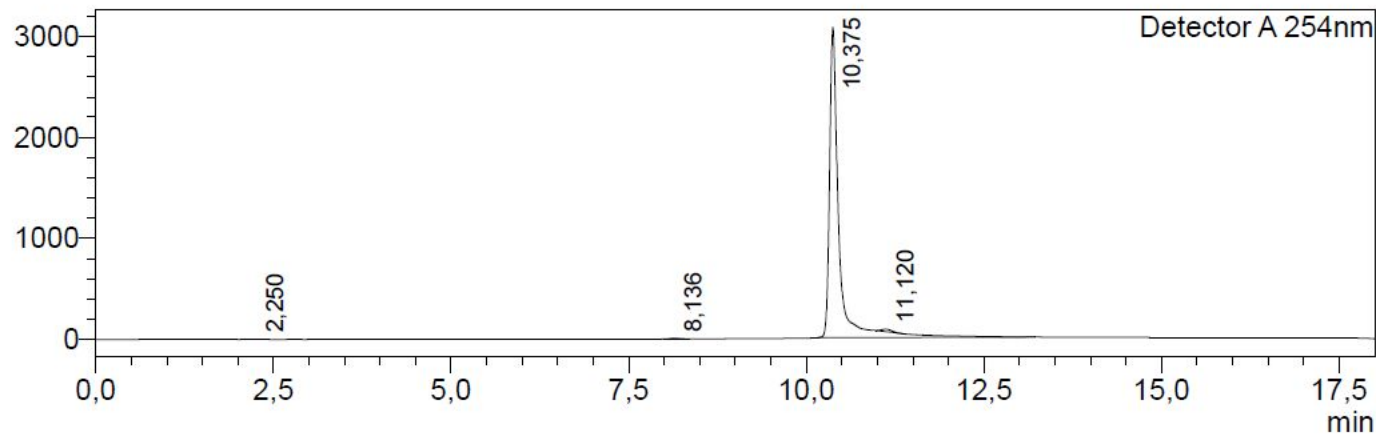

\begin{tabular}{|r|r|r|r|}
\hline \multicolumn{1}{|c|}{ Peak\# } & Ret. Time & \multicolumn{1}{|c|}{ Area } & \multicolumn{1}{|c|}{ Area\% } \\
\hline 1 & 2,250 & 10021 & 0,035 \\
\hline 2 & 8,136 & 76717 & 0,265 \\
\hline 3 & 10,375 & 28652014 & 98,917 \\
\hline 4 & 11,120 & 226937 & 0,783 \\
\hline Total & & 28965689 & 100,000 \\
\hline
\end{tabular}




\section{5b}

$\mathrm{mV}$

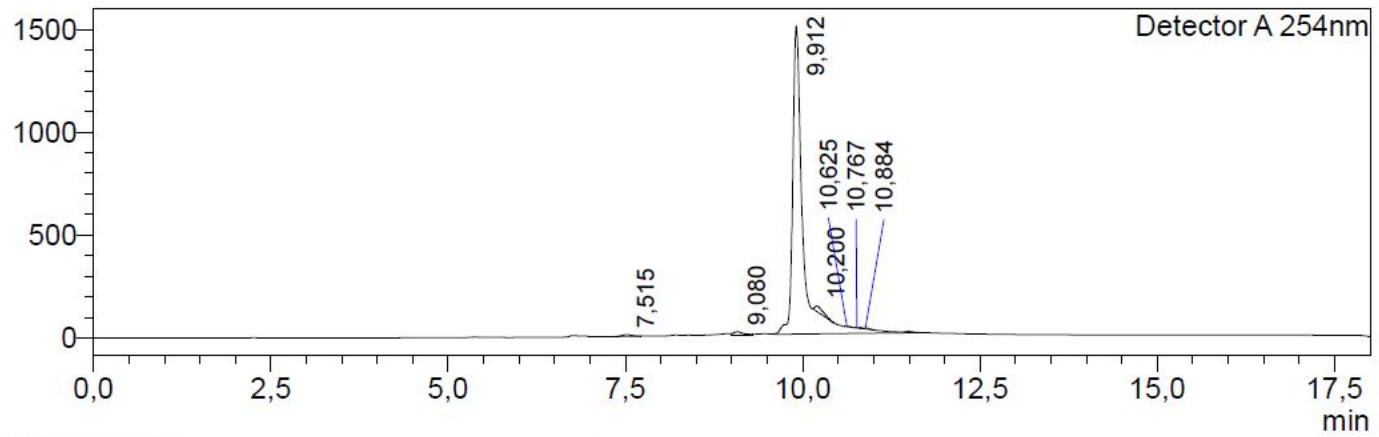

\begin{tabular}{|r|r|r|r|}
\hline Peak\# & \multicolumn{1}{|c|}{ Ret. Time } & \multicolumn{1}{c|}{ Area } & \multicolumn{1}{c|}{ Area $\%$} \\
\hline 1 & 7,515 & 67420 & 0,420 \\
\hline 2 & 9,080 & 137694 & 0,859 \\
\hline 3 & 9,912 & 15547020 & 96,964 \\
\hline 4 & 10,200 & 234969 & 1,465 \\
\hline 5 & 10,625 & 8189 & 0,051 \\
\hline 6 & 10,767 & 6089 & 0,038 \\
\hline 7 & 10,884 & 32488 & 0,203 \\
\hline Total & & 16033869 & 100,000 \\
\hline
\end{tabular}

\section{$15 c$}

$\mathrm{mV}$

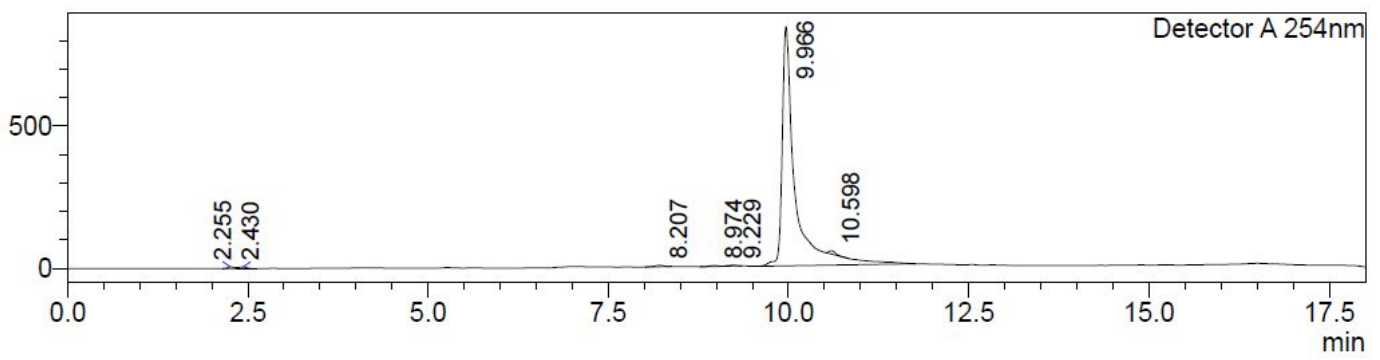

Peak Table

Detector A $254 \mathrm{~nm}$
\begin{tabular}{|r|r|r|r|r|}
\hline Peak\# & Ret. Time & Area & Height & \multicolumn{1}{c|}{ Area $\%$} \\
\hline 1 & 2.255 & 34513 & 5969 & 0.321 \\
\hline 2 & 2.430 & 43826 & 5142 & 0.408 \\
\hline 3 & 8.207 & 44663 & 5198 & 0.416 \\
\hline 4 & 8.974 & 27860 & 3231 & 0.259 \\
\hline 5 & 9.229 & 25788 & 2934 & 0.240 \\
\hline 6 & 9.966 & 10498712 & 836579 & 97.698 \\
\hline 7 & 10.598 & 70716 & 11830 & 0.658 \\
\hline Total & & 10746078 & 870883 & 100.000 \\
\hline
\end{tabular}



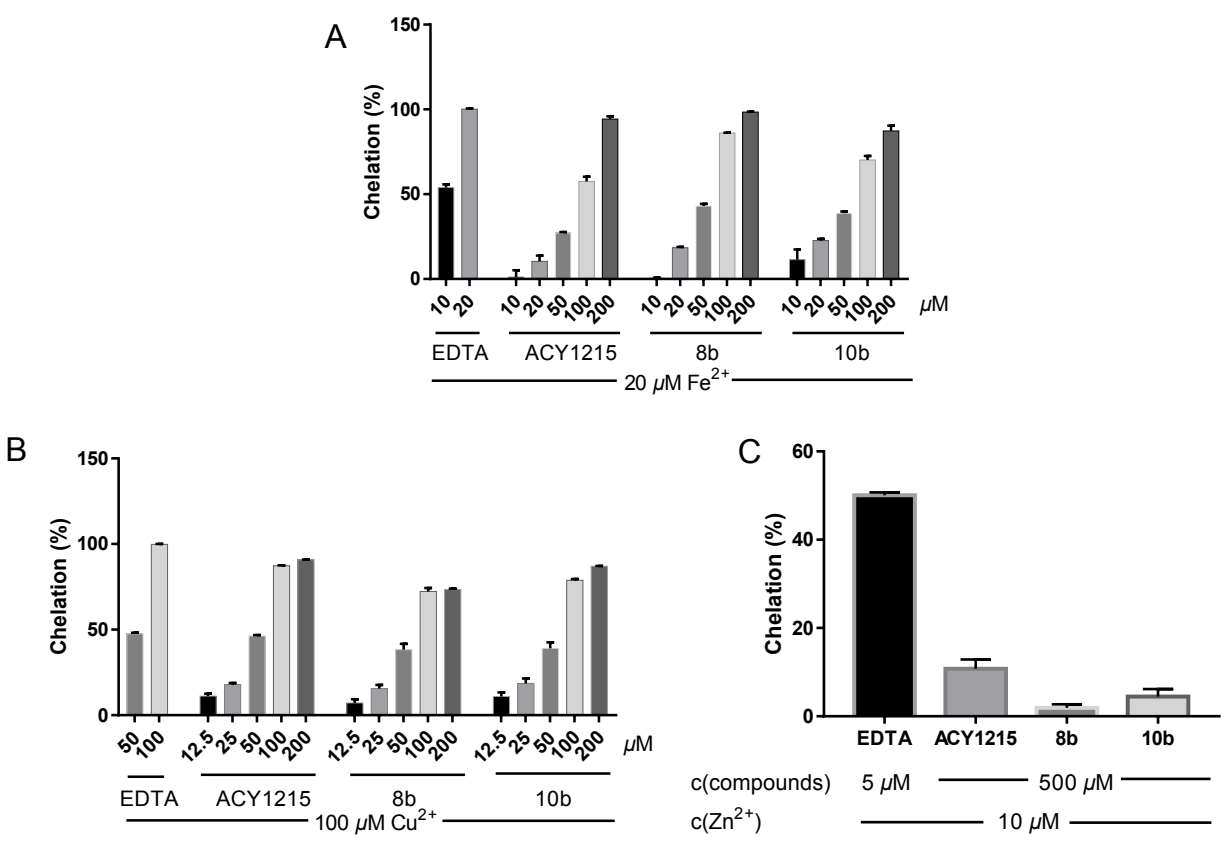

Figure S1. The chelating ratio (Mean \pm SEM) of target compounds at different concentration to $\mathrm{Fe}^{2+}, \mathrm{Cu}^{2+}$ and $\mathrm{Zn}^{2+}$. A) Target compounds (10, 20, 50, 100 and $\left.200 \mu \mathrm{M}\right)$ and EDTA (10 and $\left.20 \mu \mathrm{M}\right)$, with $\mathrm{Fe}^{2+}(20$ $\mu \mathrm{M})$ and indicator ferrozine $(62.5 \mu \mathrm{M})$; B) Target compounds (12.5, 25, 50, 100 and $200 \mu \mathrm{M})$ and EDTA (50 and $100 \mu \mathrm{M})$, with $\mathrm{Cu}^{2+}(100 \mu \mathrm{M})$ and indicator pyrocatechol violet (PV, $\left.37.5 \mu \mathrm{M}\right)$; C) Target compounds $(500 \mu \mathrm{M})$ and EDTA $(50 \mu \mathrm{M})$, with $\mathrm{Zn}^{2+}(10 \mu \mathrm{M})$ and indicator dithizone $(41.7 \mu \mathrm{M})$. 
NEUROPROTECTION AGAINST OXYTOSIS AND ATP

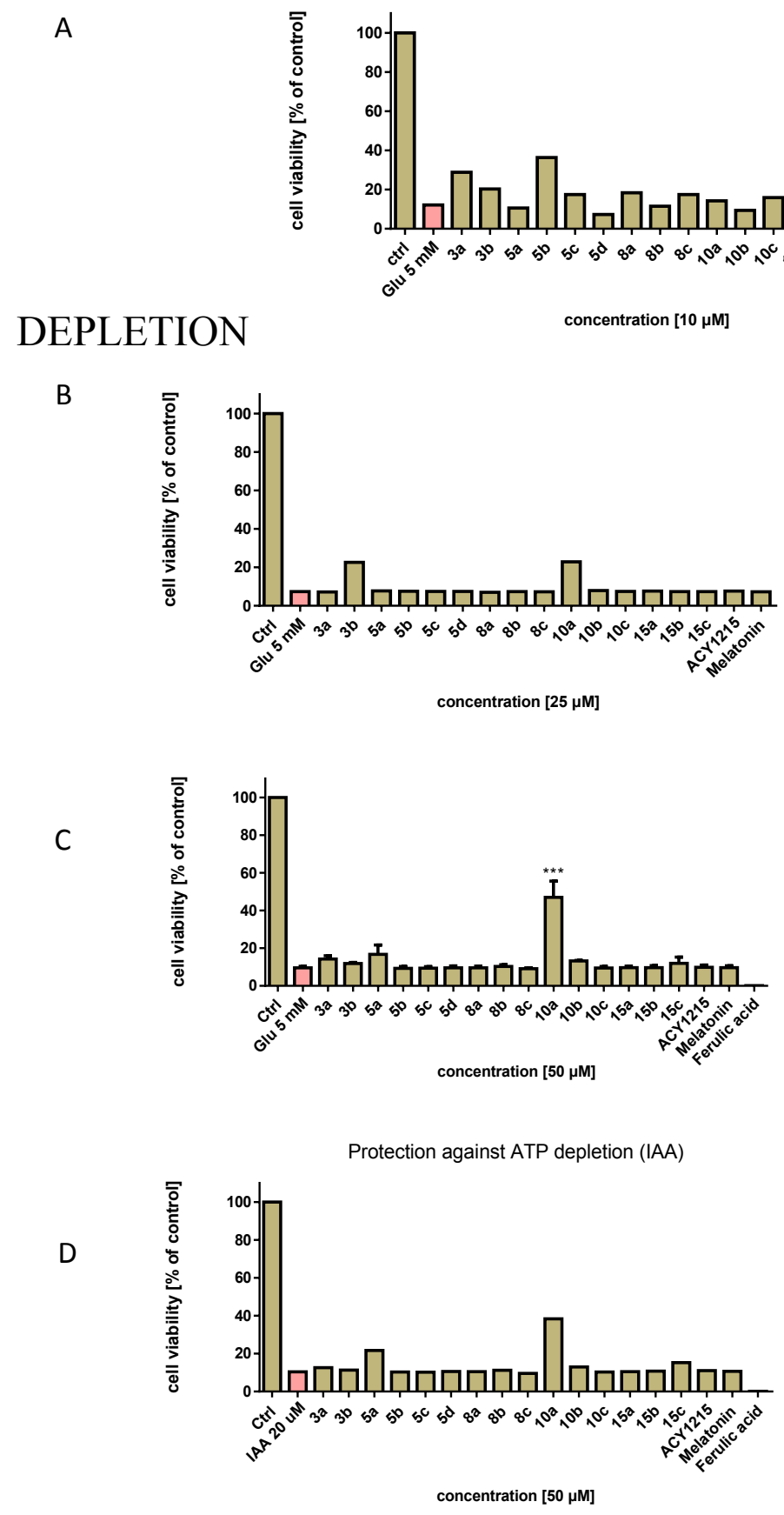

Figure S2. Neuroprotection in HT-22 cells against glutamate ( $5 \mathrm{mM})$ induced oxytosis (A, B and C) and iodoacetic acid (IAA, $20 \mu \mathrm{M}$ ) induced ATP depletion (D) in HT22 cells. Target compounds at $10 \mu \mathrm{M}$ (A), $25 \mu \mathrm{M}$ (B) and $50 \mu \mathrm{M}$ (C and D). Statistical analysis was performed applying One-way ANOVA followed by Dunnett's multiple comparison post-test. Levels of significance: ${ }^{* * *} p<0.001$ referring to cells treated with glutamate. 


\section{WEIGHT OF ANIMALS DURING IN VIVO STUDIES}

A

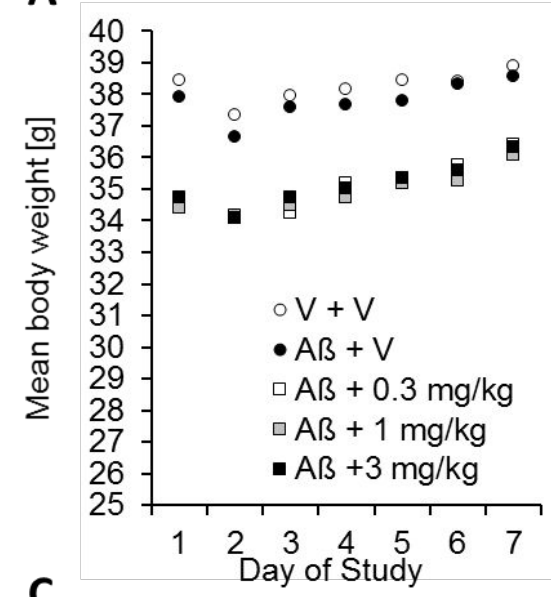

C

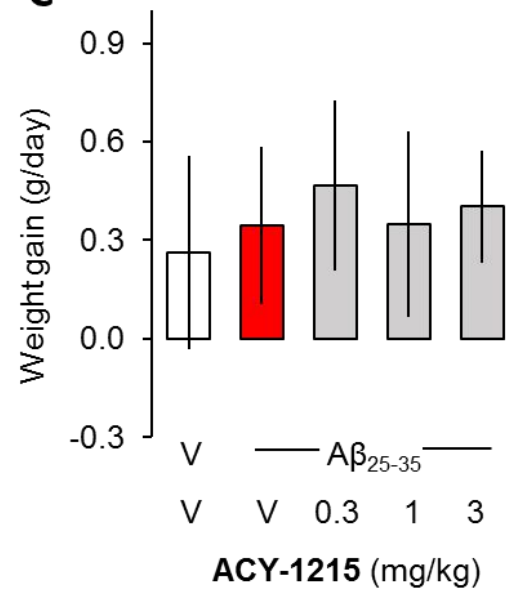

B

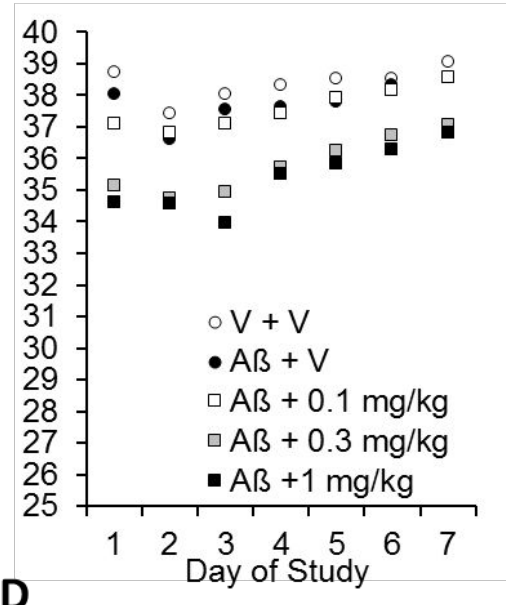

D

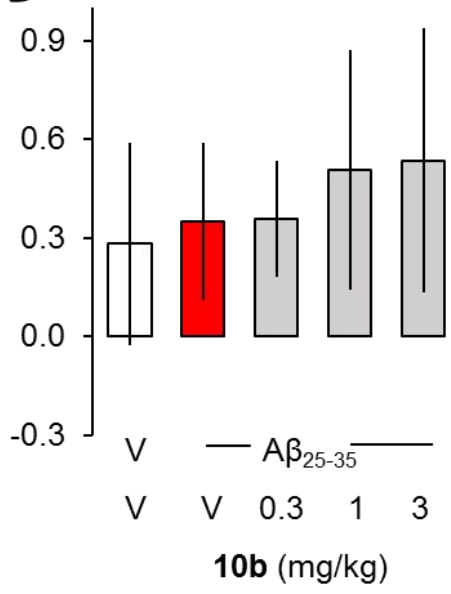

Figure S3. Development of body weight. Top panel: stress-induced weight loss is observed on day 2. Animals recovered during the following days. Data show mean. Bottom panel: average weight gain from day 2-7. Data show mean \pm SEM. ANOVA: $F_{(4,95)}=2.26, \mathrm{p}=0.07, \mathrm{n}=12-25$ in $\mathrm{B}, F_{(4,97)}=2.47, \mathrm{p}=0.05, \mathrm{n}=12-25$ in D. Data are not significantly different from $\mathrm{A} \beta+\mathrm{V}$-treated group, Dunnett's test. 


\section{COMPUTATIONAL DOCKING}

\section{Methods}

Protein and ligand preparations were carried out with the Molecular Operating Environment (MOE) 2020.09. ${ }^{1}$ The protein structure was prepared from the wellresolved crystal structure of Danio rerio (zebrafish) HDAC6 complexed with compound A (PDB 6DVM, $1.47 \AA$ ). ${ }^{2}$ As discussed by Porter et al. ${ }^{2}$, the zebrafish HDAC6 is an excellent and more readily studied surrogate of human HDAC6. Protonation states were set according to the expected ionization at $\mathrm{pH}$ 7.4. Further assessment of the ligand protonation states was achieved with Epik. ${ }^{3}$ The hydroxamic acid as zinc binding group was deprotonated to the negatively charged hydroxamate. The $\mathrm{Zn}^{2+}$ ion as well as three conserved water molecules were retained for the docking calculations. Each ligand was built in MOE and energy minimized with the MMFF94x force field in tether mode to an rms-gradient of $0.001 \mathrm{kcal} /(\mathrm{mol} \cdot \AA)$.

Docking studies were carried out with the Genetic Optimization for Ligand Docking (GOLD) program v.5.8.1.4,5 Selection of suitable genetic algorithm (GA) parameters as well as the fitness function were done after comprehensive redocking calculations. The latter were performed with a set of HDAC6 complexes cocrystallized with phenylhydroxamate ligands (6DVM, 6DVO, 6PZS, and 6PZO). ${ }^{2,6}$ Improved convergence towards reasonable binding modes was achieved with the following GA search parameters: population size 500, number of operations 500,000, crossover frequency 90, and migration frequency 20. For compounds $\mathbf{8 b}$ and $\mathbf{1 0 b}, 100$ independent GA runs were performed, using ASP and ChemPLP as scoring functions. The water molecule coordinated to the $\mathrm{Zn}^{2+}$ ion was handled in toggle mode, whereas the two water molecules next to His614 and Phe643 were kept “on". For optimal placement and orientation of water molecules during docking, a translation distance of $1 \AA$ and a "Trans spin" state were set. Constrained docking calculations were performed for compound 10b, using the phenylhydroxamate substructure as scaffold. The obtained docking poses for each ligand were clustered based on a root-mean-square-deviation 
(RMSD) of $2 \AA$ as cut-off and rescored with the scoring function DSX. ${ }^{7}$ The PyMOL Molecular Graphics System v.2.4.1. ${ }^{8}$ was used for visual inspection and figure preparation.

\section{Redocking studies of HDAC6 protein-ligand complexes}

The binding modes of the cocrystallized ligands could be reproduced with good convergence and reasonable accuracy by the top-ranked docking pose after rescoring with DSX. The obtained RMSD values with respect to the experimental reference structure were $1.03 \AA$ for $6 \mathrm{DVO}, 1.91 \AA$ for $6 \mathrm{PZS}$, and $2.83 \AA$ for $6 \mathrm{PZO}$.

Special attention was paid to $6 \mathrm{DVM}$ as it contains ligand A (according to Figure $\mathbf{1}$ of the main manuscript) and is, hence, the reference structure most closely related to compounds $\mathbf{8 b}$ and $\mathbf{1 0 b}$. This protein-ligand complex is influenced by crystal packing, because the ligand forms extensive interactions with a symmetry-related ligand molecule, including a staggered $\pi$-stacking interaction of the dimethylaniline moieties. ${ }^{2}$ In the absence of the crystal enviroment, the tolyl moiety of the ligand is entirely exposed and oriented away from the protein surface (cf. binding mode shown in green in Figure S4), a situation which is unlikely to represent the binding mode in solution. This is reflected by the docking calculations: performing the redocking in the presence of the symmetry-related molecule leads to virtually perfect reproduction of the crystallographic binding mode with an RMSD of $0.89 \AA$. In contrast, in the absence of the symmetry-related molecule, a different binding mode is obtained (shown in orange in Figure S4), in which the tolyl group is oriented toward Leu712. Although this different orientation leads to an overall RMSD of $4.31 \AA$ with respect to the crystal structure, it appears as the more reasonable binding mode in solution where the crystal environment is not present. Furthermore, a similar orientation is found for the capping groups of the investigated compounds $\mathbf{8 b}$ and, in particular, $\mathbf{1 0 b}$, as can be seen by comparison of Figure S4 with Figure 2 of the main manuscript. 


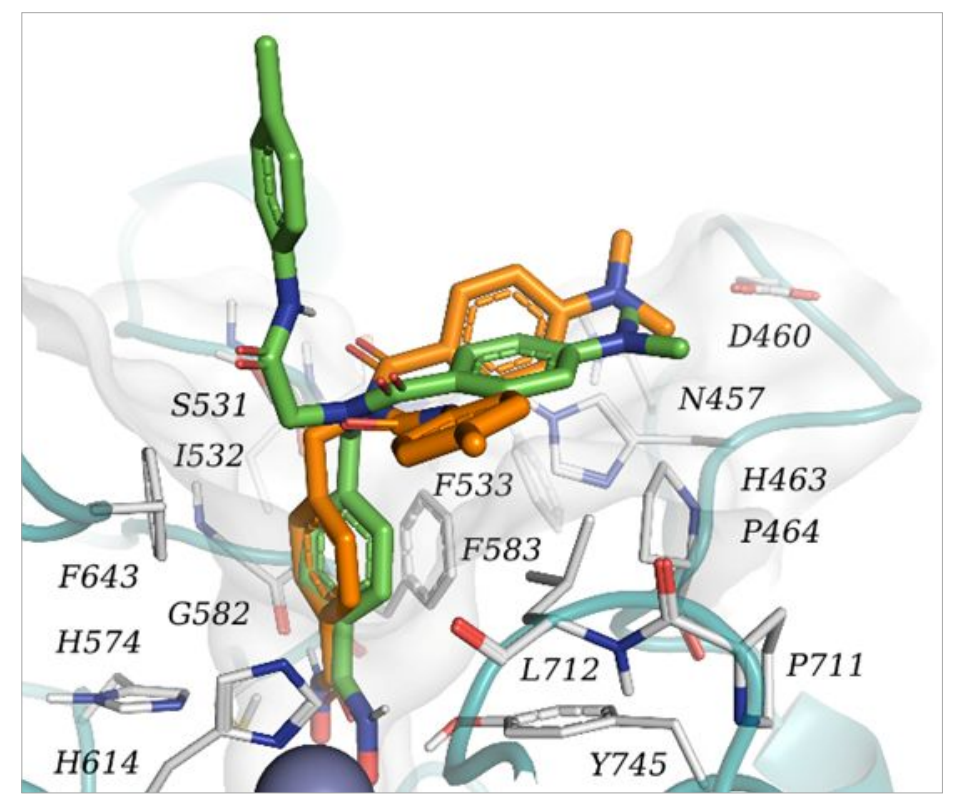

Figure S4. Docking solution (shown in orange) obtained for 6DVM without considering the symmetry-related molecule from the crystal structure in comparison to the binding mode observed in the crystal structure (shown in green).

\section{References}

1. ULC, C. C. G. Molecular Operating Environment (MOE), 2020.09, 1010 Sherbooke St. West, Suite No.910, Montreal, QC, Canada, H3A 2R7, 2021.

2. Porter, N. J.; Osko, J. D.; Diedrich, D.; Kurz, T.; Hooker, J. M.; Hansen, F. K.; Christianson, D. W., Histone Deacetylase 6-Selective Inhibitors and the Influence of Capping Groups on HydroxamateZinc Denticity. Journal of Medicinal Chemistry 2018, 61, 8054-8060.

3. Epik, Schrödinger, LLC, New York, NY, 2021.

4. Jones, G.; Willett, P.; Glen, R. C.; Leach, A. R.; Taylor, R. Development and validation of a genetic algorithm for flexible docking, Journal of Molecular Biology 1997, 267, 727-748.

5. Verdonk, M. L.; Cole, J. C.; Hartshorn, M. J.; Murray, C. W.; Taylor, R. D., Improved protein-ligand docking using GOLD. Proteins-Structure Function and Genetics 2003, 52, 609-623.

6. Reßing, N.; Sönnichsen, M.; Osko, J. D.; Schöler, A.; Schliehe-Diecks, J.; Skerhut, A.; Borkhardt, A.; Hauer, J.; Kassack, M. U.; Christianson, D. W.; Bhatia, S.; Hansen, F. K., Multicomponent Synthesis, Binding Mode, and Structure-Activity Relationship of Selective Histone Deacetylase 6 (HDAC6) Inhibitors with Bifurcated Capping Groups. Journal of Medicinal Chemistry 2020, 63, 10339-10351.

7. Neudert, G.; Klebe, G., DSX: A Knowledge-Based Scoring Function for the Assessment of ProteinLigand Complexes. Journal of Chemical Information and Modeling 2011, 51, 2731-2745.

8. Schrödinger-LLC The PyMOL Molecular Graphics System, version 2.4.1; 2021. 